\title{
Artificial Neural Network-Based Modelling and Optimization to Estimate the Fineness Modulus of the Drying Process of Sago Starch Using a Pneumatic Conveying Recirculated Dryer
}

\author{
Abadi Jading $^{\# 1}$, Nursigit Bintoro ${ }^{* 2}$, Lilik Sutiarso ${ }^{* 3}$, Joko Nugroho Wahyu Karyadi ${ }^{* 4}$ \\ ${ }^{1}$ Dr. Cand. in the Department of Agricultural and Biosystem Engineering, Faculty of Agricultural Technology, \\ Gadjah Mada University, Yogyakarta 55281, Indonesia \\ ${ }^{1}$ Department of Agricultural Technology, Faculty of Agricultural Technology, Papua University, \\ Manokwari, West Papua, 98314, Indonesia \\ 1_a_jading@yahoo.com \\ ${ }^{2,3,4}$ Department of Agricultural and Biosystem Engineering, Faculty of Agricultural Technology, \\ Gadjah Mada University, Yogyakarta 55281, Indonesia \\ 2bintoro@ugm.ac.id \\ 3lilik-soetiarso@ugm.ac.id \\ 4joko@ugm.ac.id
}

\begin{abstract}
A pneumatic conveying recirculated dryer is very suitable for sago starch drying and thus the present research has designed a PCRD machine. It aimed to develop an Artificial Neural Network (ANN) model to estimate the fineness modulus of sago starch dried using a PCRD machine. The designed ANN model structure used consisted of 12 input neuron, three variations of hidden layers, and 1 output neuron, with three topological variations, namely 12-5-5-1-1, 12-10-10-1-1, and 12-15-15-1-1, as well as used the learning algorithm backpropagation. The validity test for the ANN model generated an $\mathbf{R}_{\text {trained }}^{2}$

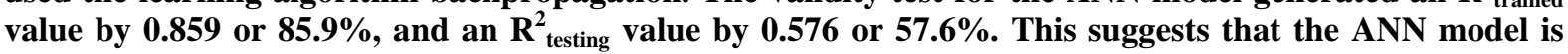
valid enough to be employed to estimate the fineness modulus of sago starch dried using a PCRD machine. Optimization of the ANN model for the training and testing process generated the lowest MRE and MAE values for the variable $v_{u}$, namely by $3.785 \%$ and $0.0004 \%$, and $L_{A c r b}$, namely by $13.214 \%$ and $0.0012 \%$, respectively. This indicates that variables with a significant effect on determination of the fineness modulus are the speed of the air of the dryer and the length of the upper outlet pipe in the recirculation cyclone.
\end{abstract}

Keywords - Artificial neural network, Fineness modulus, Modelling, Pneumatic conveying recirculated dryer, Sago starch

\section{Introduction}

Sago starch is one of carbohydrate sources obtained from sago plants (Metroxylon sagu). Wet sago starch contains carbohydrates by approximately $50 \%$. As for dried sago starch, the percentage of carbohydrates it contains ranges from 84 to $89 \%$ of the total composition in sago starch. The physical properties of wet sago starch are solid, sticky, containing water by 40 to $50 \%$ wb, having a granule size by 5 to $57.5 \mu \mathrm{m}$, and having a gelatinization temperature by approximately $60-75^{\circ} \mathrm{C}([1]$, [2]).

Wet sago starch can be processed into dried starch through the drying process. The process of having sago starch dried using artificial dryers had been undertaken by [3], [4], [5]. However, the process of having sago starch dried using those dryers generated less optimal results. To overcome this problem, this research had designed a pneumatic conveying recirculated dryer (PCRD) machine. This engine was developed based on pneumatic dryers which are very suitable for the drying of materials containing a high moisture content such as sago starch.

To determine the fineness level of sago starch dried using PCRD, the Artificial Neural Network (ANN) model was developed to estimate the value of the fineness modulus (FM) based on variations in the variables of pneumatic drying processes using continued recirculation of a substance. Reference [6] define an FM value as an index to indicate the fineness level of a particular substance. Fineness levels of a particular substance are classified into three groups, namely coarse, medium and fine, in which the finer a substance is, the smaller the FM value is. 
The artificial neural network (ANN) refers to an artificial representation of the human brain, which has several advantages, such as modelling of the drying process. ANN application to estimate the FM value of materials based on variations in the parameters of the pneumatic drying process with continuous recirculation of materials has never been conducted. However, the application of an ANN in drying processes is more commonly used to estimate the moisture content, activation energy, and the effective moisture diffusivity of particular materials. Research using ANN models to examine the relationship between drying process parameters and the moisture content of particular materials is among others conducted by [7], [8], [9], [10], [11], [12], [13]. This research aimed to develop an Artificial Neural Network (ANN) model to estimate the fineness modulus of sago starch dried using a PCRD machine according to variations in the variables of the pneumatic drying process with continued materials recirculation.

\section{MATERIALS AND METHODS}

The materials used in this research were wet sago starch with initial moisture contents of 21 , 31, and $41 \%$ wb and a diameter of $0.00236 \mathrm{~m}(2.36 \mathrm{~mm})$. The wet sago was dried using a PCRD machine designed and developed in this research. This PCRD machine consisted of seven main components (units), namely the LPGfuelled heating stove, the disintegrator (centrifugal blower with the 3-phase electric motor drive, $380 \mathrm{~V}, 2 \mathrm{hp}$ ), the feeder for input materials (saw-edged with the 1-phase electric motor drive, $220 \mathrm{~V}, 1 \mathrm{hp}$ ), the drying pipe the continuously recirculated, the manifold (the recirculation cyclone and the material separator, and the centrifugal blower with the 1-phase electric motor drive, $220 \mathrm{~V}, 1 \mathrm{hp}$ ), the material output cyclone, and the control panel. The scheme of the PCRD machine is presented in Fig 1.

The sago starch dried through the drying process using the PCRD machine was later sieved using the sieving machine manufactured by Endecotts (test sieve shaker) LTD London S.W.19, England. The sieving machine is comprised of sieves with a size ranging from 3/6 to 100 mesh $(9.55$ to $0.15 \mathrm{~mm})$. Data on dried sago starch sieving results were used to calculate the fineness modulus value of the materials $\left(\mathrm{FM}_{\mathrm{ob}}\right.$ ) using Equation (1) ([6]).

$$
F M_{o b}=\frac{\text { Total cumulative } \% \text { of the remaining }}{100}
$$

The variables of pneumatic drying processes with continued recirculation of materials used in the PCRD machine included the moisture content of the input materials $\left(\mathrm{M}_{\mathrm{ib}}\right)$, the speed of the air of the dryer $\left(\mathrm{v}_{\mathrm{u}}\right)$, the air temperature of the dryer $\left(T_{u 3}\right)$, the length of the recirculation pipe $\left(L_{p}\right)$, the height of the recirculation cyclone cylinder $\left(\mathrm{L}_{\mathrm{scrb}}\right)$, the diameter $\left(\mathrm{D}_{\text {Acrb }}\right)$, and the length of the upper outlet pipe in the recirculation cyclone $\left(\mathrm{L}_{\mathrm{Acrb}}\right)$, the speed of the air of the blower in the recirculation cyclone $\left(\mathrm{v}_{\mathrm{ucrb}}\right)$, and the material input capacity $\left(\mathrm{Q}_{\mathrm{ib}}\right)$. As for the constant variables, they were comprised of the diameter of the input materials $\left(\mathrm{D}_{\mathrm{ib}}\right)$, gravitational acceleration (g), and drying or recirculation time $\left(\mathrm{t}_{\mathrm{r}}\right)$. The values for the level and limit of the variables used as the input and output layers in the network structure of the ANN model to estimate the fineness modulus of the materials $\left(\mathrm{FM}_{\mathrm{ob}}\right)$ are presented in Table I.

The network structure used to estimate the fineness modulus of the materials $\left(\mathrm{FM}_{\mathrm{ob}}\right)$ was comprised of multiple layers (multi-layer net) with multi-input single output. The ANN network structure used consisted of 12 input layer neurones, three hidden layers with three topological variations, namely 12-5-5-1-1, 12-10-10-1-1, and 12-15-15-1-1, and 1 output layer neuron using the transfer function logsig or logsigmoid. The learning algorithm used was backpropagation. The ANN network structure can be seen in Fig. 2.

The resulting network structure of the ANN model was tested and trained using the observation data with the software neural network toolbox Matlab R2014a ([12]). There were a total of 81 data per dataset used for training and testing the model in the present research. The data were classified into two, namely 54 ANN model training datasets and 27 ANN model testing datasets. The procedures for collection and analysis of the data can be seen in Fig. 3.

An optimal ANN model can be determined based on the values of the mean relative error (MRE) and the mean absolute error (MAE) ([7], [12], [13]. Those values were used to determine the effect of the variables of pneumatic drying processes with continuous recirculation of materials on the ANN model. MRE and MAE values were calculated using Equations (2) and (3) ([7]).

$$
\begin{gathered}
M R E=\frac{\sum_{i=1}^{N}\left|\frac{F M_{o b-p r e d, i}-F M_{o b-o b s v, i} \mid}{F M_{o b-o b s v, i}}\right|}{N} \chi 100 \\
M A E=\frac{\sum_{i=1}^{N}\left|F M_{o b-p r e d, i}-F M_{o b-o b s v, i}\right|}{N} \\
\text { Vol } 9 \text { No 4 Aug-Sep 2017 }
\end{gathered}
$$


where $\mathrm{FM}_{\mathrm{ob}-\mathrm{prd}}$ indicates the estimated fineness modulus of the materials, $\mathrm{FM}_{\mathrm{ob}-\mathrm{obsv}}$ refers to the observed fineness modulus of the materials, and $\mathrm{N}$ is the number of data used for training and testing the ANN model.

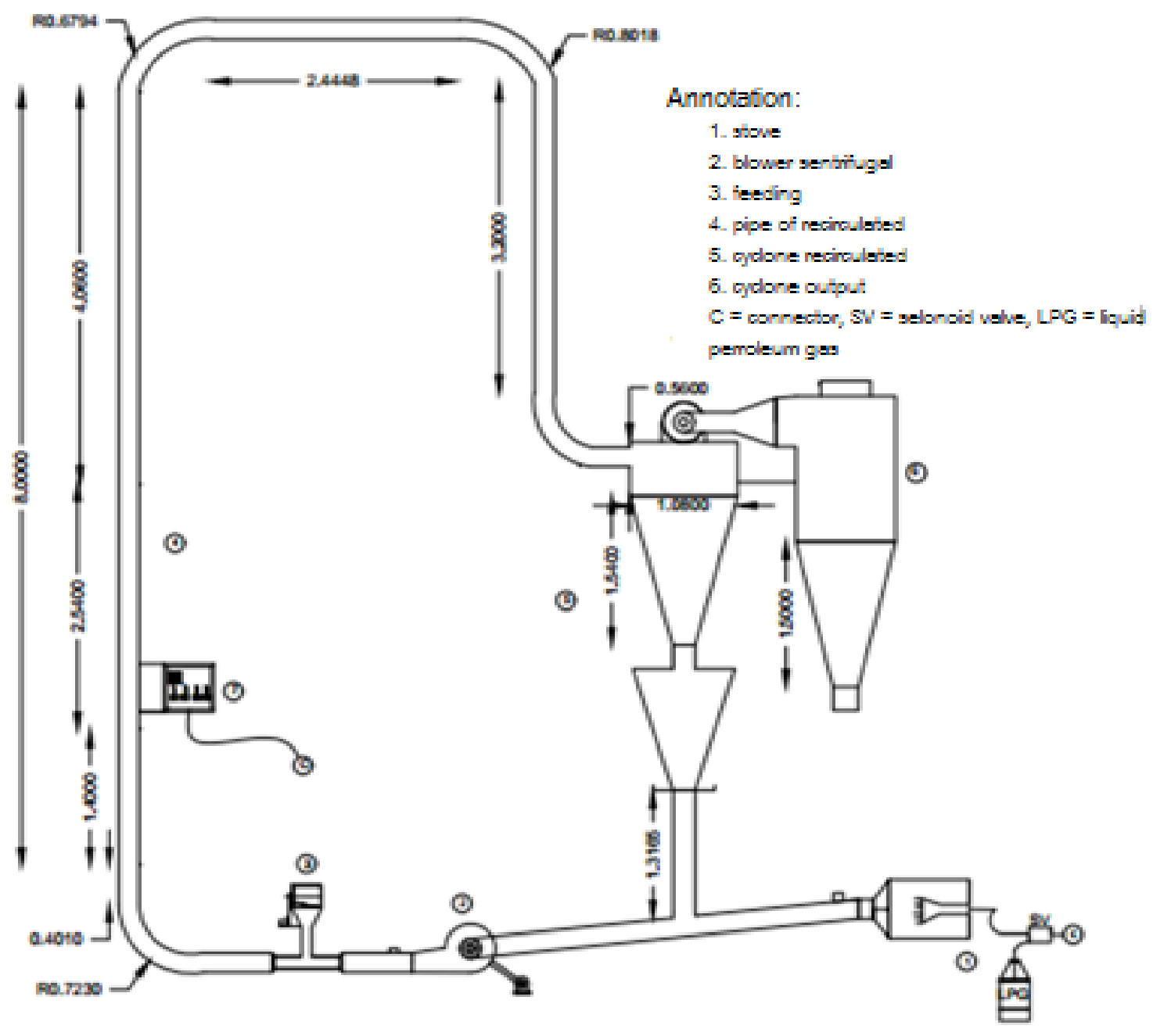

Fig. 1. The schematic drawing of a PCRD machine

TABLE I The Input and Output Variables to Estimate the $\mathrm{FM}_{\mathrm{ob}}$ Value

\begin{tabular}{|c|c|c|c|c|}
\hline Input variabels & Units & Minimum & Maximum & Level \\
\hline $\mathrm{M}_{\mathrm{ib}}$ & $\% \mathrm{bb}$ & 21 & 41 & 3 \\
\hline $\mathrm{v}_{\mathrm{u}}$ & $\mathrm{m} / \mathrm{s}$ & 15 & 31 & 3 \\
\hline $\mathrm{T}_{\mathrm{u} 3}$ & ${ }^{\circ} \mathrm{C}$ & 75 & 125 & 3 \\
\hline $\mathrm{L}_{\mathrm{p}}$ & $\mathrm{m}$ & 9.38 & 13.38 & 3 \\
\hline $\mathrm{L}_{\mathrm{ccrb}}$ & $\mathrm{m}$ & 0.27 & 0.81 & 3 \\
\hline $\mathrm{D}_{\text {Acrb }}$ & $\mathrm{m}$ & 0.1016 & 0.220 & 3 \\
\hline $\mathrm{L}_{\text {Acrb }}$ & $\mathrm{m}$ & 0.2 & 0.65 & 3 \\
\hline $\mathrm{v}_{\mathrm{ucrb}}$ & $\mathrm{m} / \mathrm{s}$ & 10.75 & 15.75 & 3 \\
\hline $\mathrm{Q}_{\mathrm{ib}}$ & $\mathrm{kg} / \mathrm{s}$ & 0.00208 & 0.00417 & 3 \\
\hline $\mathrm{D}_{\mathrm{ib}}$ & $\mathrm{m}$ & 0.00236 & - & - \\
\hline $\mathrm{g}$ & $\mathrm{m} / \mathrm{s}$ & 9.8 & - & - \\
\hline $\mathrm{t}_{\mathrm{r}}$ & $\mathrm{s}$ & 420 & - & - \\
\hline Output variabel & & & & \\
\hline $\mathrm{FM}_{\mathrm{ob}}$ & - & - & - & - \\
\hline
\end{tabular}




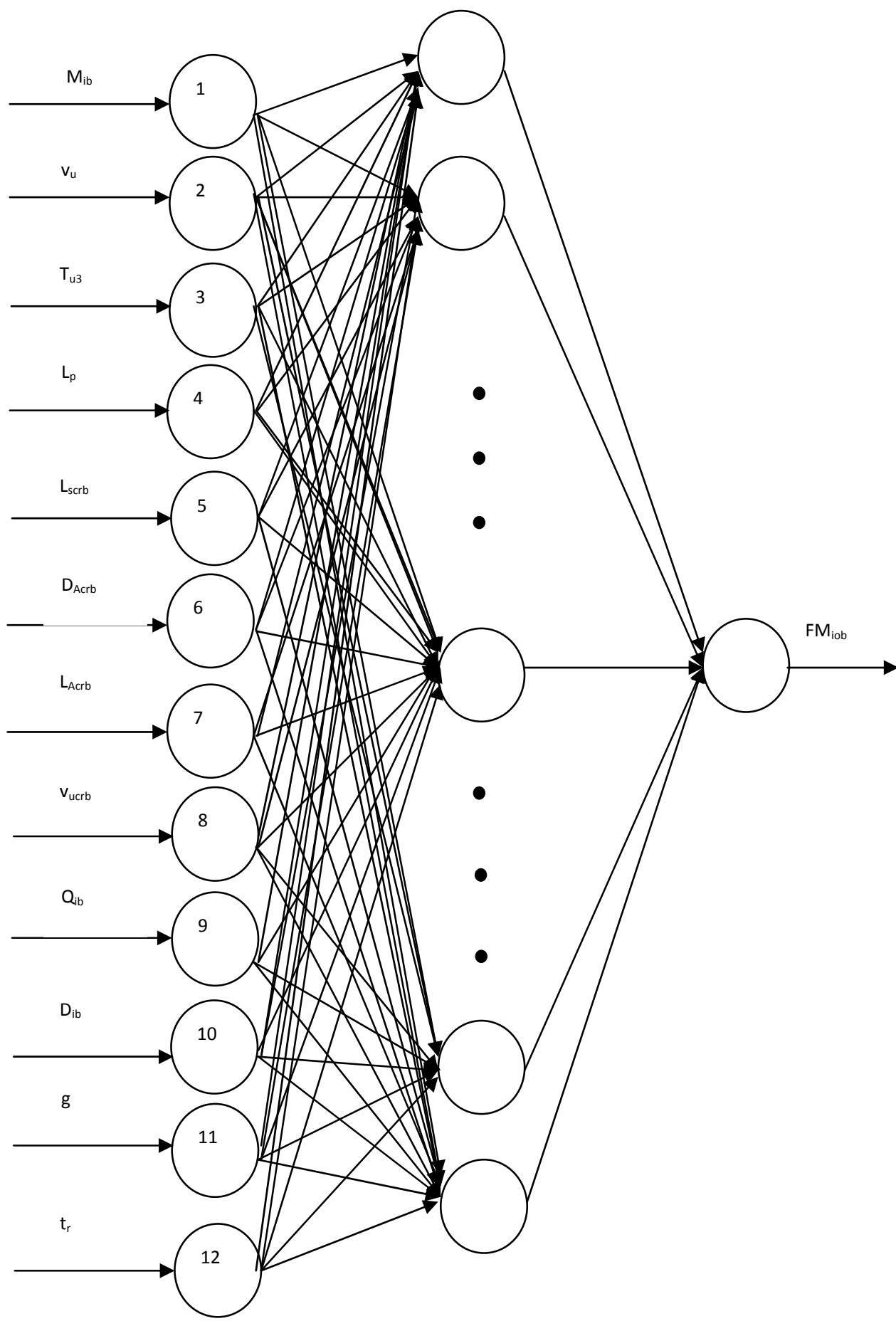

Fig. 2. The network structure of the ANN model to estimate the $\mathrm{FM}_{\mathrm{ob}}$ value 


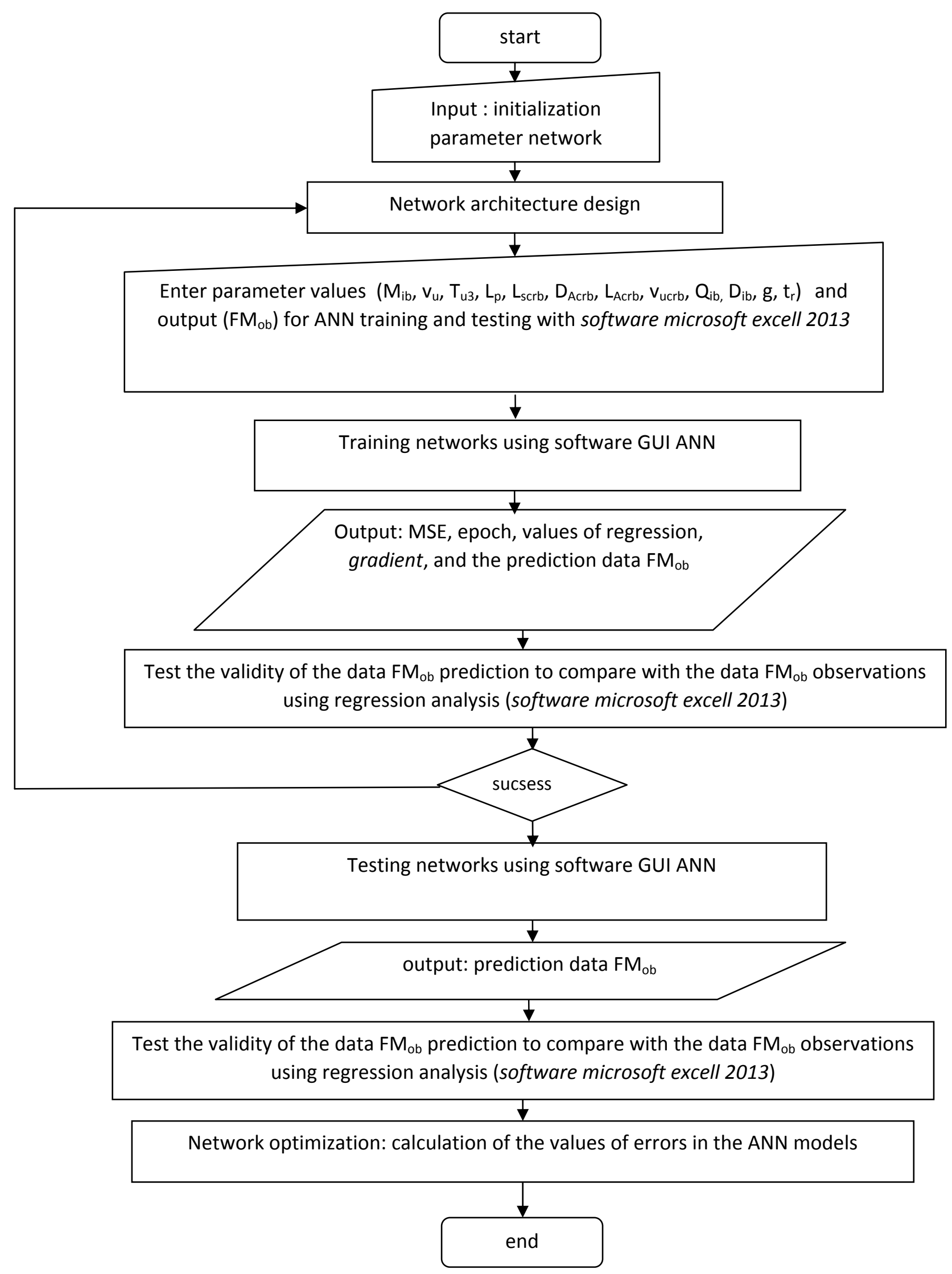

Fig. 3. The Procedures for collection and analysis data on the ANN model to estimate 


\section{RESULTS AND DISCUSSION}

The training and testing of the ANN model to estimate the $\mathrm{FM}_{\mathrm{ob}}$ value employed 81 observation datasets (54 datasets for training and 27 datasets for testing). Results of the ANN model training and testing using the software neural network toolbox in MATLAB R2014a generated the mean square error (MSE) value or the performance index value for the ANN model network by 0.00237 and the regression value by 0.927 . The number of iterations (epochs) required to generate that MSE value was 40 times for the topology 12-5-5-1-1, 16 times for the topology 12-10-10-1-1, and 13 times for the topology 12-15-15-1-1.

Results of the ANN model network training and testing using the hidden layer topology 12-5-5-1-1 can be seen in Fig. 4. The training and testing results were comprised of the network structure, the learning algorithm, the progress and plot, the gradient value, and the value of $\mathrm{R}_{\text {simulation. }}$. It took 40 times of iterations (epochs) with

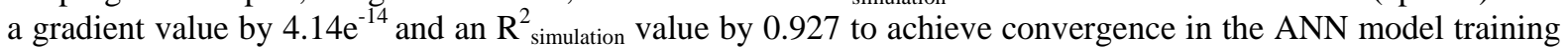
process.

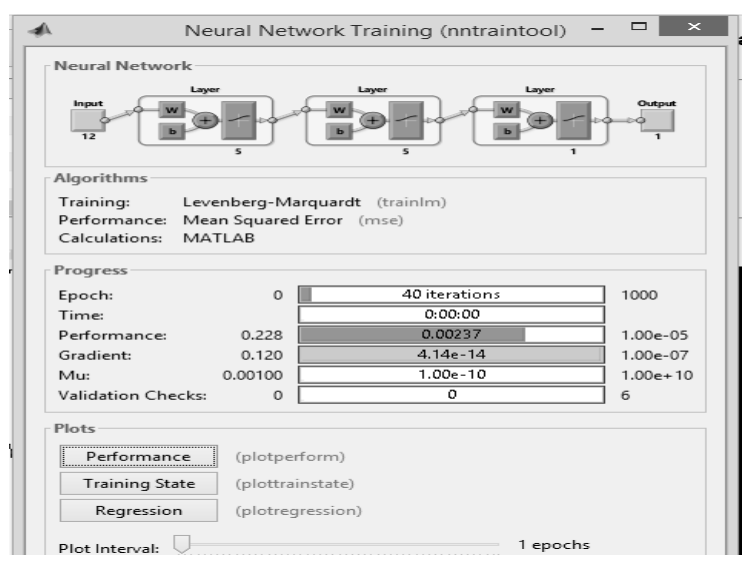

a)

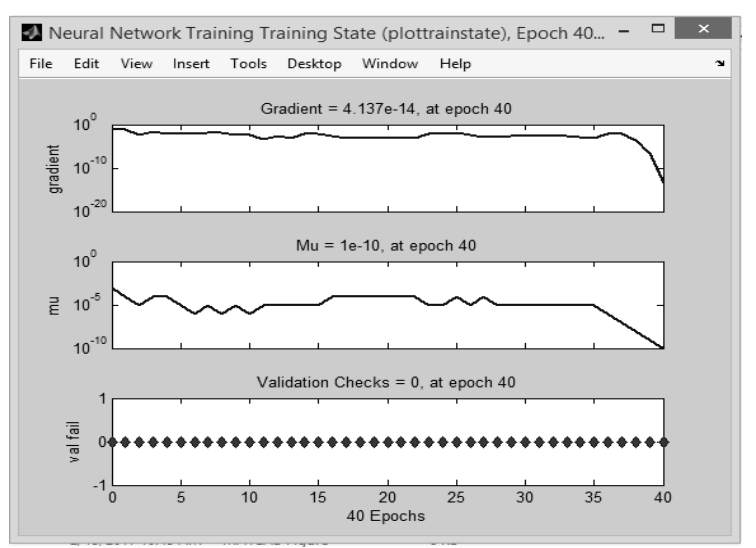

c)

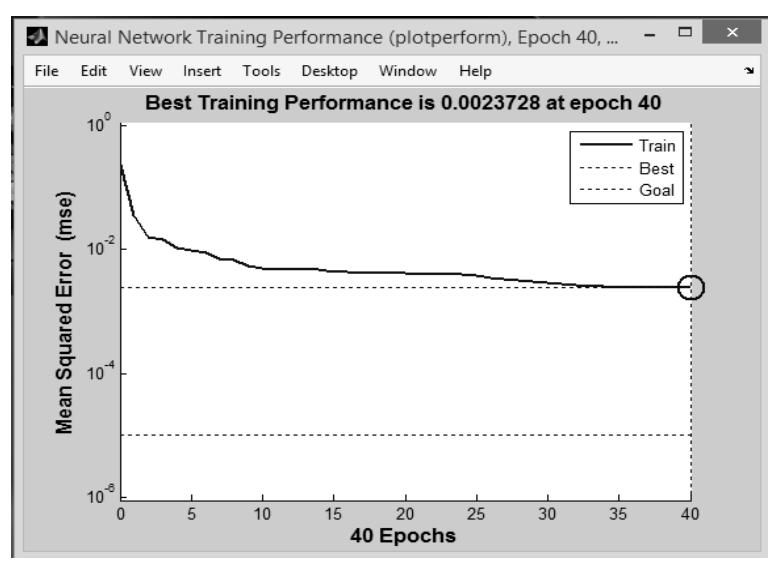

b)

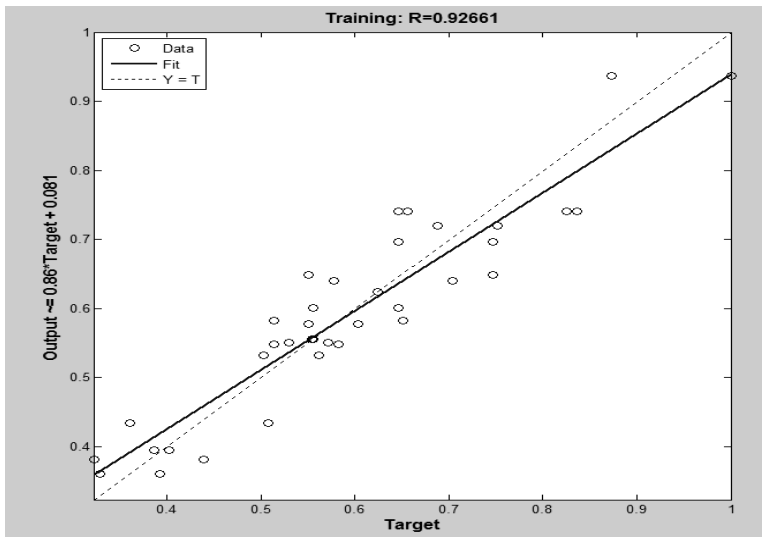

d)

Fig. 4. The topology 12-5-5-1-1: a) the number of epochs, b) performance, c) gradient, d) the regression value

Results of the ANN model network training and testing using the hidden layer topology 12-10-10-1-1 can be seen in Fig. 5. Fig. 5 presents the network structure, the learning algorithm, the progress and plot, the gradient value, and the value of $\mathrm{R}^{2}$ simulation. It took 16 times of iterations (epochs) with a gradient value by $4.21 \mathrm{e}^{-11}$ and an $\mathrm{R}^{2}$ simulation value by 0.927 to achieve convergence in the ANN model training process.

Results of the ANN model network training and testing using the hidden layer topology 12-15-15-1-1 can be seen in Fig. 6. Fig. 6 presents the network structure, the learning algorithm, the progress and plot, the gradient value, and the value of $\mathrm{R}^{2}$ simulation. It took 13 times of iterations (epochs) with a gradient value by $5.66 \mathrm{e}^{-08}$ and an $\mathrm{R}^{2}$ simulation value by 0.927 to achieve convergence in the ANN model training process. 


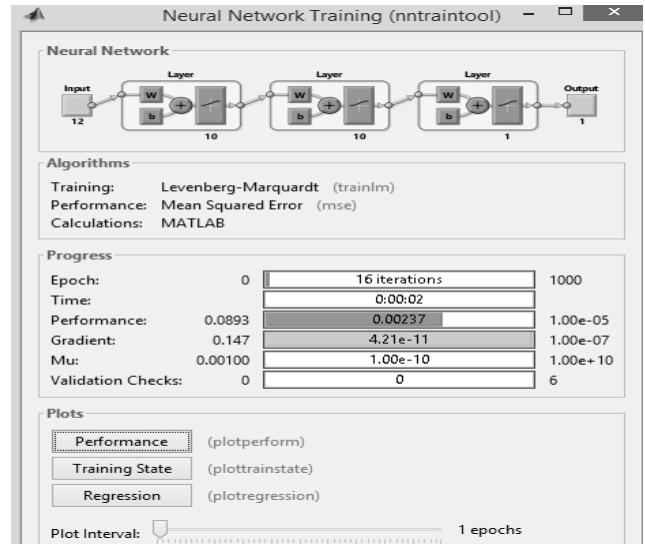

a)

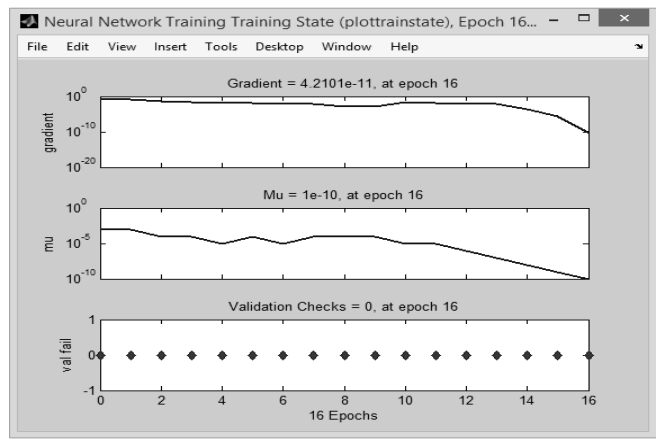

c)

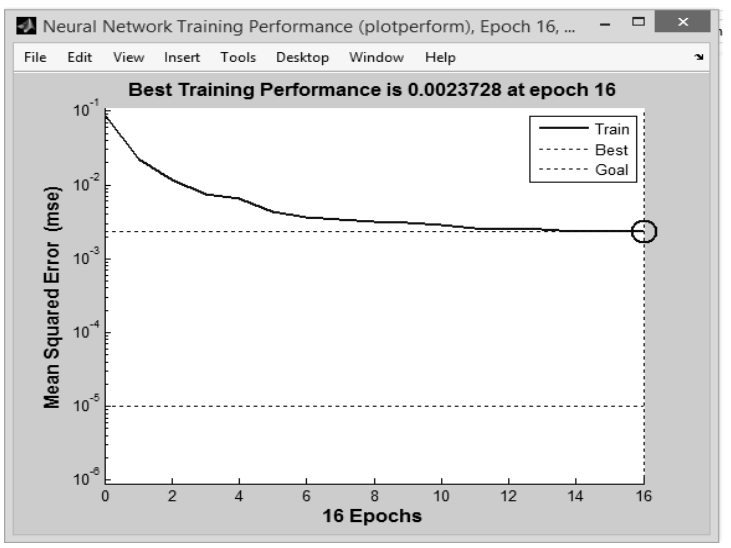

b)

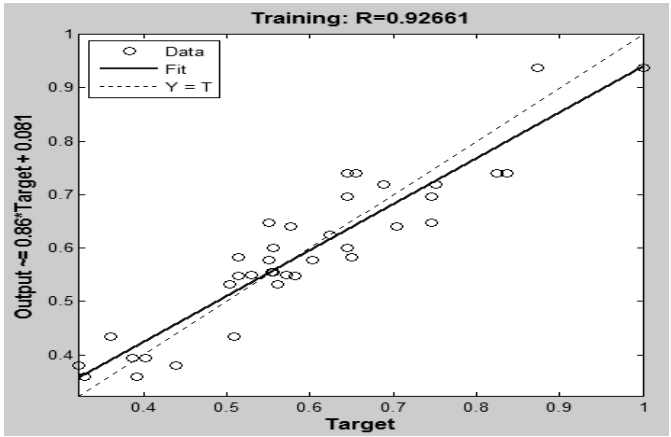

d)

Fig. 5. The topology 12-10-10-1-1: a) the number of epochs, b) performance, c) gradient, d) the regression value

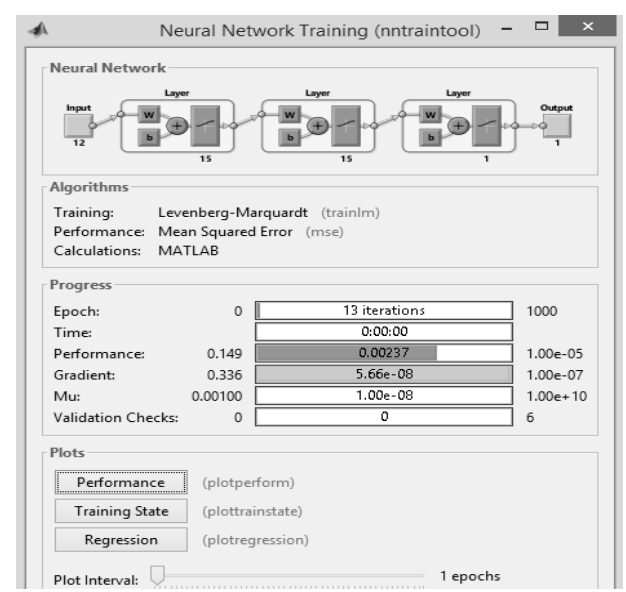

a)

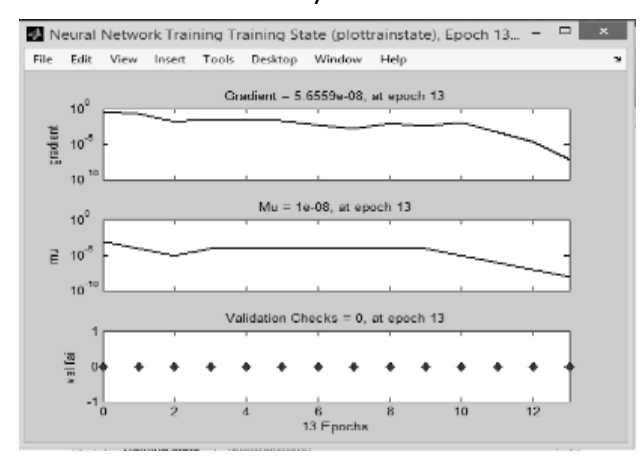

c)

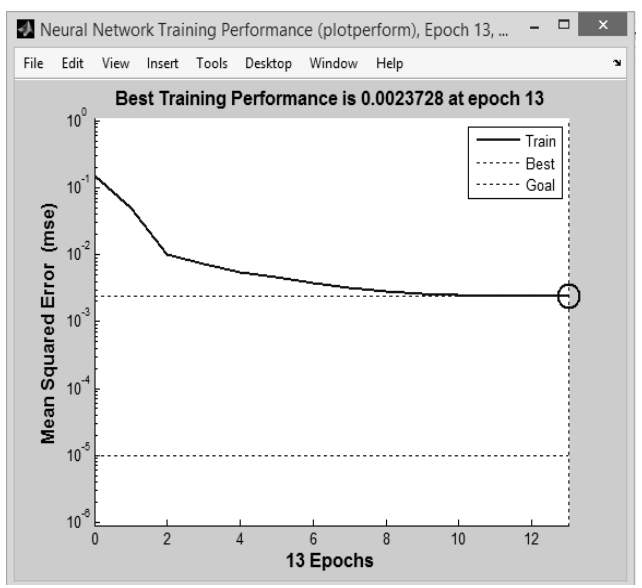

b)

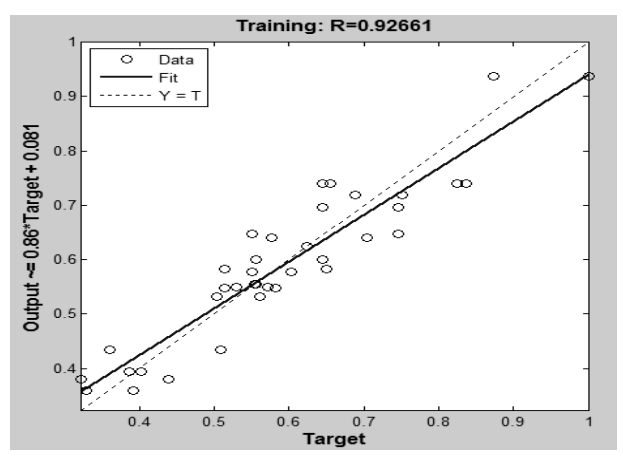

d) 
Fig 6. The topology 12-15-15-1-1: a) the number of epochs, b) performance, c) gradient, d) the regression value

Results of the topological variation of the ANN model network used to estimate $\mathrm{FM}_{\mathrm{ob}}$ suggest that the best topology to generate an MSE value is the network structure 12-15-15-1-1 and thus, this topology was chosen for the ANN model testing process. The graph illustrating the comparison between the estimated $\mathrm{FM}_{\mathrm{ob}}$ and the observed $\mathrm{FM}_{\mathrm{ob}}$ resulting from the training and testing of the ANN model can be seen in Figs. 7 and 8 . The graphs of the estimated $\mathrm{FM}_{\mathrm{ob}}$ and the observed $\mathrm{FM}_{\mathrm{ob}}$ tend to have a similar pattern, the distance between the variation parameters is less close to one another, except for several parameters. As for the graph illustrating the comparison between the estimated $\mathrm{FM}_{\mathrm{ob}}$ and the observed $\mathrm{FM}_{\mathrm{ob}}$ resulting from the model testing, it tends to have the same pattern as the graph resulting from the training.

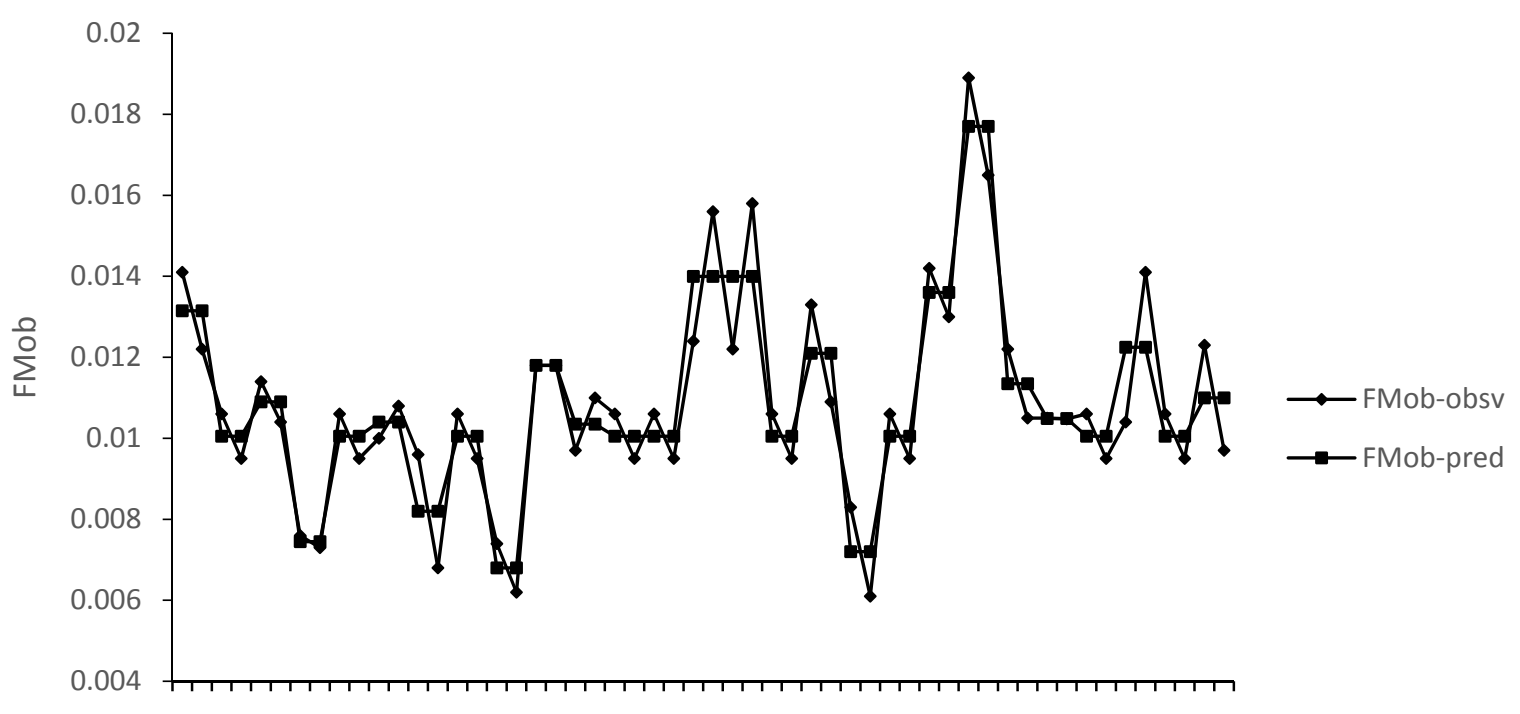

1357911131517192123252729313335373941434547495153

$\mathrm{N}$ data

Fig. 7. The graph the comparison between $\mathrm{FM}_{\mathrm{ob}-\text { pred }}$ and $\mathrm{FM}_{\mathrm{ob}-\mathrm{obsv}}$ of the model training

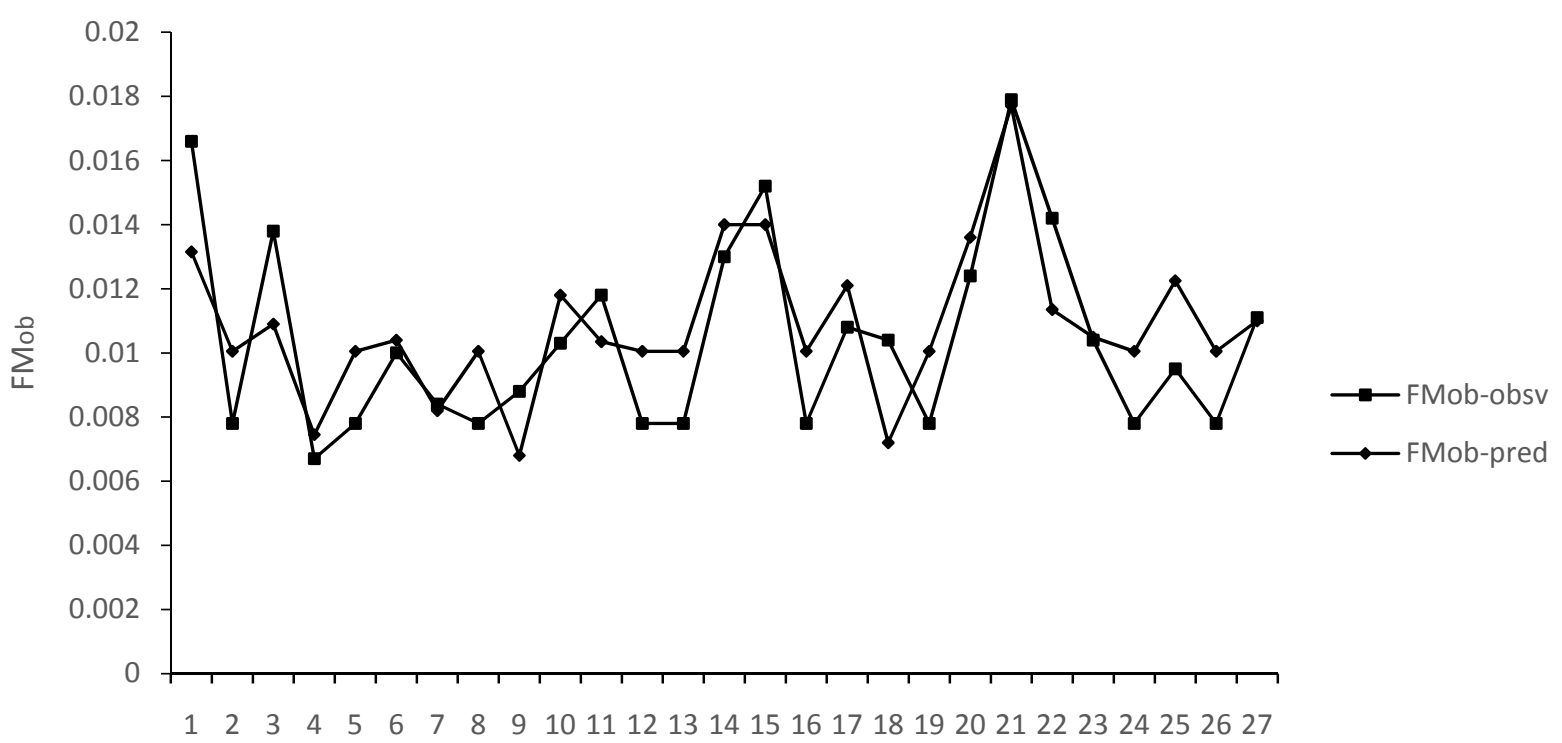

$\mathrm{N}$ data

Fig. 8. The graph the comparison between $\mathrm{FM}_{\mathrm{ob}-\text { pred }}$ and $\mathrm{FM}_{\mathrm{ob}-\mathrm{obsv}}$ of the model testing 
The regression equation of the comparison between the estimated $\mathrm{FM}_{\mathrm{ob}}$ and the observed $\mathrm{FM}_{\mathrm{ob}}$ resulting from the ANN model training is $\mathrm{FM}_{\mathrm{ob}}$-pred $=0.858 \mathrm{FM}_{\mathrm{ob}-\mathrm{obsv}}+0.0015$, with the value of the coefficient of determination $\left(\mathrm{R}_{\text {trained }}^{2}\right)$ by 0.859 . The value by 0.0015 is a constant which suggests that in the absence of the addition of the observed $\mathrm{FM}_{\mathrm{ob}}$, the estimated $\mathrm{FM}_{\mathrm{ob}}$ will increase by 0.0015 . As for the value by 0.858 , it is the regression coefficient which indicates that for each addition of the observed $\mathrm{FM}_{\mathrm{ob}}$, the estimated $\mathrm{FM}_{\mathrm{ob}}$ will increase by 0.858 .

The regression equation of the comparison between the estimated $\mathrm{FM}_{\mathrm{ob}}$ and the observed $\mathrm{FM}_{\mathrm{ob}}$ resulting from the ANN model testing is $\mathrm{FM}_{\mathrm{ob}}$-obsv $=0.578 \mathrm{FM}_{\mathrm{ob} \text {-pred }}+0.0048$, with the value of the coefficient of determination $\left(\mathrm{R}_{\text {tested }}^{2}\right)$ by 0.576 . The value by 0.0048 is a constant which suggests that in the absence of the addition of the estimated $\mathrm{FM}_{\mathrm{ob}}$, the observed $\mathrm{FM}_{\mathrm{ob}}$ will increase by 0.0048 . As for the value by 0.578 , it is the regression coefficient which indicates that for each addition of the estimated $\mathrm{FM}_{\mathrm{ob}}$, the observed $\mathrm{FM}_{\mathrm{ob}}$ will increase by 0.578 .

The graph of the regression analysis results for the relationship between the estimated $\mathrm{FM}_{\mathrm{ob}}$ and the observed $\mathrm{FM}_{\mathrm{ob}}$ resulting from the ANN model training and testing can be seen in Figs. 9 and 10. The graph shows that the relationship between the estimated $\mathrm{FM}_{\mathrm{ob}}$ and the observed $\mathrm{FM}_{\mathrm{ob}}$ in the ANN model training and testing processes is quite valid as the obtained values of the coefficient of determination $\left(\mathrm{R}_{\text {trained }}^{2}\right)$ approaches 1 , namely $0.859(85.9 \%)$ and $0.576(57.6 \%)$. As for the model of the relationship between the estimated FM and the observed FM developed by [6] generated the value of the coefficient of determination $\left(R^{2}\right)$ by 0.787 . It means that the ANN model generated in this research is able to estimate changes in $\mathrm{FM}_{\mathrm{ob}}$ in the drying process of materials using the PCRD machine.

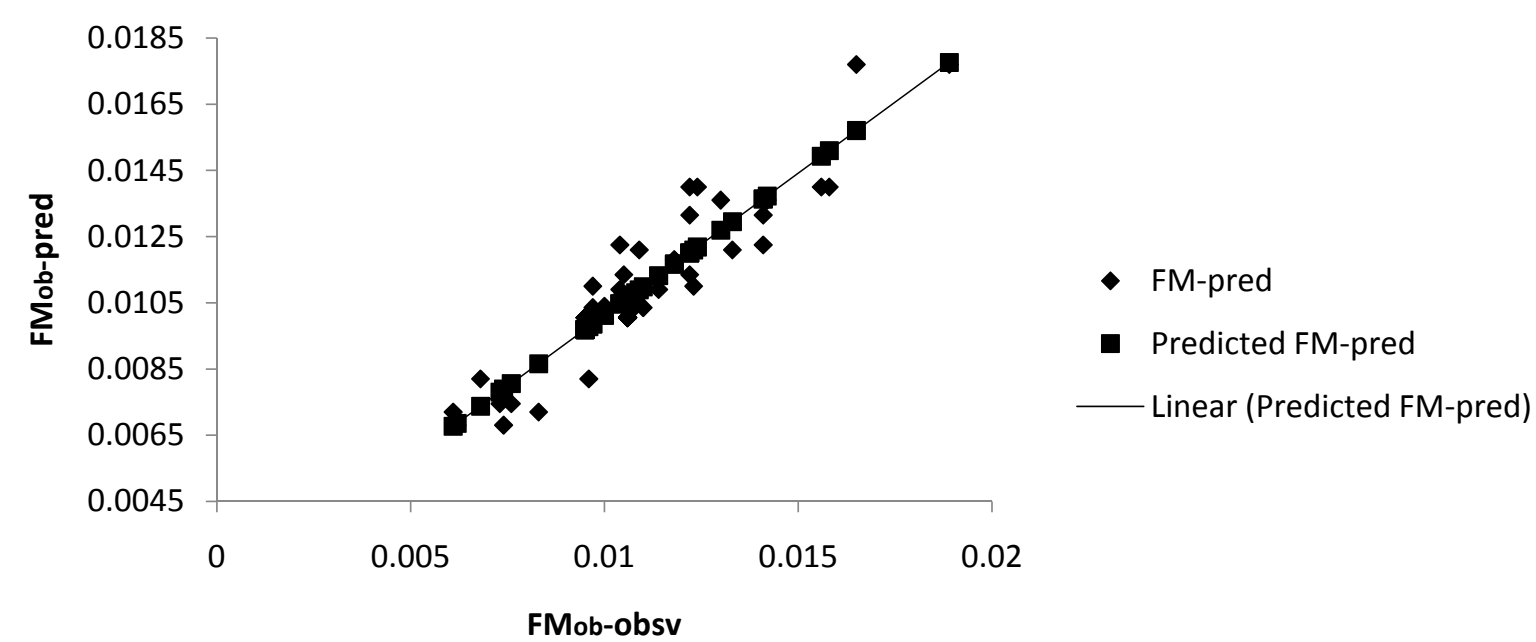

Fig. 9. The graph regression between $\mathrm{FM}_{\mathrm{ob}-\text { pred }}$ and $\mathrm{FM}_{\mathrm{ob}-\mathrm{obss}}$ resulting from the ANN model training

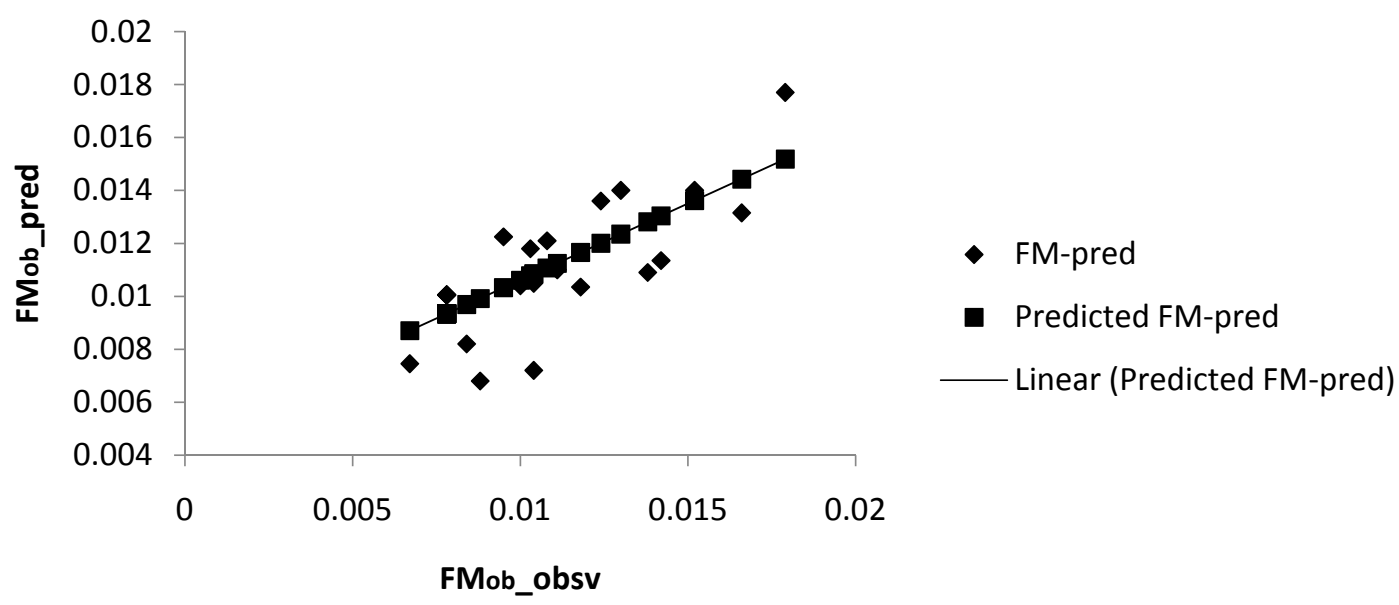

Fig. 10. The graph regression between $\mathrm{FM}_{\mathrm{ob}-\mathrm{pred}}$ and $\mathrm{FM}_{\mathrm{ob}-\mathrm{obsv}}$ resulting from the $\mathrm{ANN}$ model testing 
Analysis results for the optimization of the ANN model used in this research showed that the MAE and MRE values generated by ANN model training were equal to $0.0008 \%$ and $7.279 \%$, respectively. These MAE and MRE values were analyzed using Equations (2) and (3) which were used to estimate the error value of the ANN model. As for the ANN model testing, it generated an MAE value by $0.0017 \%$ and an MRE value by $16.926 \%$. To determine the variation parameter with the most significant effect on pneumatic drying processes with continuous recirculation of materials, an optimization analysis was undertaken to determine MAE and MRE values of each variation parameter [12] [13]. Results of the optimization analysis can be seen in Table II.

TABLE II MAE and MRE Values of the $\mathrm{FM}_{\mathrm{ob}}$ Model of ach Variation Variabels

\begin{tabular}{|c|c|c|c|}
\hline & Parameter & MAE (\%) & MRE (\%) \\
\hline \multirow[t]{9}{*}{ Training } & $\mathrm{M}_{\mathrm{ib}}$ & 0.0007 & 5.783 \\
\hline & $\mathrm{v}_{\mathrm{u}}$ & 0.0004 & 3.785 \\
\hline & $\mathrm{T}_{\mathrm{u} 3}$ & 0.0009 & 10.656 \\
\hline & $\mathrm{L}_{\mathrm{p}}$ & 0.0004 & 3.931 \\
\hline & $\mathrm{L}_{\mathrm{scrb}}$ & 0.0013 & 10.047 \\
\hline & $\mathrm{D}_{\text {Acrb }}$ & 0.0009 & 10.383 \\
\hline & $\mathrm{L}_{\text {Acrb }}$ & 0.0008 & 5.373 \\
\hline & $\mathrm{V}_{\mathrm{ucrb}}$ & 0.0005 & 4.372 \\
\hline & $\mathrm{Q}_{\mathrm{ib}}$ & 0.0012 & 10.976 \\
\hline \multirow[t]{9}{*}{ Testing } & $\mathrm{M}_{\mathrm{ib}}$ & 0.0029 & 23.548 \\
\hline & $\mathrm{v}_{\mathrm{u}}$ & 0.0011 & 14.680 \\
\hline & $\mathrm{T}_{\mathrm{u} 3}$ & 0.0015 & 17.985 \\
\hline & $\mathrm{L}_{\mathrm{p}}$ & 0.0017 & 18.566 \\
\hline & $\mathrm{L}_{\mathrm{scrb}}$ & 0.0015 & 14.811 \\
\hline & $\mathrm{D}_{\text {Acrb }}$ & 0.0023 & 23.884 \\
\hline & $\mathrm{L}_{\text {Acrb }}$ & 0.0012 & 13.214 \\
\hline & $\mathrm{v}_{\text {ucrb }}$ & 0.0017 & 16.594 \\
\hline & $\mathrm{Q}_{\mathrm{ib}}$ & 0.0017 & 19.565 \\
\hline
\end{tabular}

The data presented in Table 2 show that the variable $v_{u}$ generated the lowest MRE value, i.e. by 3.785\%. As for the ANN model testing, the variable $\mathrm{L}_{\text {Acrb }}$ generated the lowest MRE value, i.e. by $13.214 \%$. Results of the ANN model training revealed that the parameter of the speed of the air of the dryer $\left(\mathrm{v}_{\mathrm{u}}\right)$ with the most significant effect on changes in $\mathrm{FM}_{\mathrm{ob}}$ during the drying process. This is because the blower which blows the dryer air also served to reduce the size of materials during the drying process. The smaller the MRE value of the variable $\mathrm{v}_{\mathrm{u}}$ is, the better the ability of the ANN model network to estimate the fineness modulus value of the materials. As for the ANN model testing process, it is revealed that the variable with the most significant effect was the length of the upper outlet pipe of the recirculation cyclone $\left(\mathrm{L}_{\mathrm{Acrb}}\right)$. While results of the dimensional analysis undertaken by [6] obtained the ratio of the dryer's temperature to the materials' temperature which affected the drying process of cassava flour using a pneumatic dryer. This indicates that the recirculation process of materials using the PCRD engine is vital to determine the fineness level of materials.

\section{CONCLUSION}

This research generated an ANN model to estimate the most optimal fineness modulus, which is the topology 12-15-15-1-1. The MSE value generated by the ANN model was equal to 0.927 with the total number of epoch of 13 times. Results of the validity test for the ANN model showed that the values of the coefficient of determination were equal to 0.859 or $85.9 \%$ and 0.576 or $57.6 \%$ for the training process $\left(\mathrm{R}_{\text {trained }}^{2}\right)$ and the testing process $\left(\mathrm{R}_{\text {tested }}^{2}\right.$ ), respectively. The resulting model validity value was slightly low, especially in the process of model testing. However, the ANN model can be used to estimate the fineness modulus value of the sago starch drying process using the PCRD machine. Results for the optimization analysis of the ANN model for each variable of the variation in the drying process revealed that the variable $\mathrm{v}_{\mathrm{u}}$ generated the lowest MRE value resulting from ANN model training. As for the smallest MRE value resulting from ANN model testing, it was generated by the variable $L_{\text {Acrb }}$. These indicated that the drying process variables with the most significant effect on the ANN model to estimate the fineness modulus value of sago starch were the speed of the air of the dryer and the length of the upper outlet pipe in the recirculation cyclone of this PCRD machine. 


\section{ACKNOWLEDGEMENT}

We would like to thank for Directorate Research and Community Service, Ministry of Research, Technology, and Hinger Education which has assisted this research through a Doctoral Dissertation Research in 2017, and EMP and TPP laboratory Technician Staff Departement of Agricultural Engineering and Biosystems, Gadjah Mada University, as well as field assistant.

\section{REFERENCES}

[1] R.S. Singhal, J.F. Kennedy, S.M. Gopalakrishnan, A. Kaczmarek, C.J. Knill, and P.F. Akmar, "Industrial production, processing, dan utilization of sago palm-derived products,” Carbohydrate Polymers, vol. 72, pp. 1-20, Augt. 2008.

[2] A. Jading, E.F. Tethool, P. Payung, and S. Gultom, "Psychochemical characteristics of sago starch obtained from fluidized bed drying using solar and biomass powered cross flow fluidized bed dryer,” Reaktor, vol.13, pp. 155-164, June 2011.

[3] W.P. Aman W.P, A. Jading, and M.K. Roreng, "The prototipe of rotary dryer type heat sourced biomass for sago starch processing industry in Papua,” in Proc.National Seminar Insinas, 2013, paper , p. 494-502.

[4] A. Jading, P. Payung, W.P. Aman, and E.F. Tethool, "Development and technical finansial analysis of sago starch dryer agro cross flow fluidized model to support sago agroindustry in Papua,” Jurnal Teknologi Industri Pertanian, vol. 24, pp.137-147, Apr. 2014.

[5] A.Jading, P. Payung, and Reniana, "Study on technical-economic of sago starch dryer model of cross flow vibro fluidized bed," Agritech, vol. 34, pp. 448-455, Nov. 2014.

[6] Y. Witdarko, N. Bintoro, B. Suratmo, and B. Rahardjo, "Modeling on mechanical cassava flour drying process by using pneumatic dryer: correlation of fineness modulus and drying process variable,” Agritech, vol. 35, pp. 481-487, Nov. 2015.

[7] P. Poonnoy, A.Tansakui, and M. Chinnan, "Artificial neural network modeling for temperature and moisture content prediction in tomato slices undergoing microwave-vacuum drying,” Journal of Food Science, vol. 72, pp. E42-E47, 2007.

[8] S. Shrivastav and B.K. Kumbhar, "Modeling and optimization for prediction of moisture content, drying rates, and moisture ratio," International Journal Agricultural \& Biologi Engineering, vol. 2, pp. 58-64, March 2009.

[9] A.E.S. Kassem, M.A. Al-Sulaiman, A.E.M. Aboukarima, and S.S. Kassem, "Predicting drying efficiency during solar drying process of grapes cluster in a box dryer using artificial neural network,” Australian Journal of Basic and Applied Science, vol.5, pp. 230-241, 2011.

[10] A.S. Motevali, R.A. Younji, N. Chayjan, Aghilinategh, and A. Banakar, "Drying kinetics of dill leaves in a convective dryer," International Agrophys, vol. 27, pp. 39-47, 2013.

[11] N.J. Singh and R.K. Pandey, "Neural network approaches for prediction of drying kinetics during drying of sweet potato,” Agricultural Engineering International (CIGR Journal), vol. 13, pp. 1-12, 2011.

[12] M. Kaveh and R.A Chayjan, "Prediction of some physical and drying properties of terebinth fruit (Pistacia Atlantica L.) using artificial neural networks,” Acta. Pol. Technol. Aliment, vol. 13, pp. 65-78, 2014.

[13] R.A. Chayjan, M. Kaveh, and S. Khayati, "Modeling some drying characteristics of sour cherry (Prunus cerasus L.) under infrared radiation using mathematical models and artificial neural networks,” Agricultural Engineering International Journal, vol.16, pp. 265279, March 2014.

\section{AUTHOR PROFILE}

Abadi Jading is a Dr. Cand. in the Departement of Agricultural Engineering and Biosystems, Gadjah Mada University. He is a lecturer in Departement of Agricultural Technology, Papua University.

Dr. Nursigit Bintoro is an associate Professor of Departement of Agricultural Engineering and Biosystems, Gadjah Mada University.

Prof. Dr. Lilik Sutiarso is a Professor of Departement of Agricultural Engineering and Biosystems, Gadjah Mada University

Dr. Joko Nugroho Wahyu Karyadi is an associate Professor of Departement of Agricultural Engineering and Biosystems, Gadjah Mada University. 